\title{
Organized Hematoma of the Maxillary Sinus: Rapid Progression and Complications
}

\author{
Tae Mi Yoon, Dong Hoon Lee, Seung Beom Kim, and Sang Chul Lim \\ Department of Otorhinolaryngology-Head and Neck Surgery, Chonnam National University Medical School and Hwasun Hospital, \\ Hwasun, Korea
}

\author{
상악동 기질화 혈종의 빠른 진행 및 합병증 \\ 윤태미 · 이동훈 · 김승범 · 임상철 \\ 전남대학교 의과대학 화순전남대학교병원 이비인후과학교실
}

\author{
Received March 25, 2015 \\ Revised June 1, 2015 \\ Accepted June 2, 2015 \\ Address for correspondence \\ Sang Chul Lim, MD, PhD \\ Department of Otorhinolaryngolo- \\ gy-Head and Neck Surgery, \\ Chonnam National University \\ Medical School and Hwasun \\ Hospital, 322 Seoyang-ro, \\ Hwasun-eup, Hwasun 58128, Korea \\ Tel $+82-61-379-7758$ \\ Fax $+82-61-379-8199$ \\ E-mail limsc@chonnam.ac.kr
}

An organized hematoma of the maxillary sinus (OHMS) is a rare, benign lesion with locally destructive behavior. Although various clinical manifestations of OHMS have been reported previously, their associated complications and rapid progression have not yet been described. Herein, we report a case of OHMS that was further complicated by facial and orbital abscesses. Intensive treatment was necessary to prevent complications and progression of the condition. Korean J Otorhinolaryngol-Head Neck Surg 2016;59(2):150-4

Key Words Abscess $\cdot$ Epistaxis $\cdot$ Hematoma $\cdot$ Maxillary sinus.

\section{Introduction}

An organized hematoma of the maxillary sinus (OHMS), also known as a pseudotumor, ${ }^{1)}$ hematoma, ${ }^{2)}$ hematoma-like mass, ${ }^{3)}$ and organizing hematoma, ${ }^{4)}$ presents as an enlarging maxillary sinus mass which is associated with local bone destruction and which mimics a malignancy. However, it has been reported previously that cases of OHMS have benign clinical manifestations and do not recur or present with further complications after complete surgical evacuation. ${ }^{3-9)}$ Herein, we report a case of OHMS which was complicated by facial and orbital abscesses. The OHMS showed marked enlargement and extensive bone destruction that had occurred during an 8-month period. We believe that this case will facilitate an understanding of the rapid progression of OHMS, as well as outline the risks posed by the condition.

\section{Case}

An 88-year-old woman presented with a 3-month history of left-sided, recurrent nasal bleeding. She also complained of left-sided nasal obstruction, nasal purulence, and headache. The patient's medical history was unremarkable except that she had previously had a cataract of the left eye, which had caused significant visual loss. She has never taken anticoagulants such as aspirin or warfarin. Endoscopy revealed a polypoid mass which bled readily occupying the left nasal cavity. In addition, CT scans showed an expansile, heterogeneous, enhancing mass in the left maxillary sinus (Fig. 1). We assumed this was an OHMS, and planned endoscopic sinus surgery accordingly. We also intended to perform a preoperative biopsy to dismiss the possibility of a paranasal neoplasm. However, the patient declined further evaluation and was lost to follow-up. After 8 months, she sought assistance in the 
emergency department with a 3 day history of left severe facial swelling, orbital pain, and fever. Decreased visual acuity, severe exophthalmos, absent ocular movements, and elevated intraocular pressure were noted upon ophthalmologic examination. CT scans revealed a markedly enlarged mass with extensive bone destruction in the left maxillary sinus, as well as a facial abscess and orbital abscesses (Fig. 2). A friable, darkreddish blood clot and thick fibrous granular tissue filled the left nasal cavity and maxillary sinus (Fig. 3). In addition, there was a small amount of pus-like discharge between the blood clot and the mass. We performed urgent endoscopic sinus surgery, during which the mass was completely removed via a middle meatal antrostomy. During the surgery, we also drained the orbital abscess endonasally, and the facial abscess via an additional alotomy incision. Empiric antibiotic treatment was started using ceftriaxone and clindamycin; Klebsiella pneumoniae was isolated postoperatively and shown to be sensitive to the selected antibiotics. Histopathological evaluation
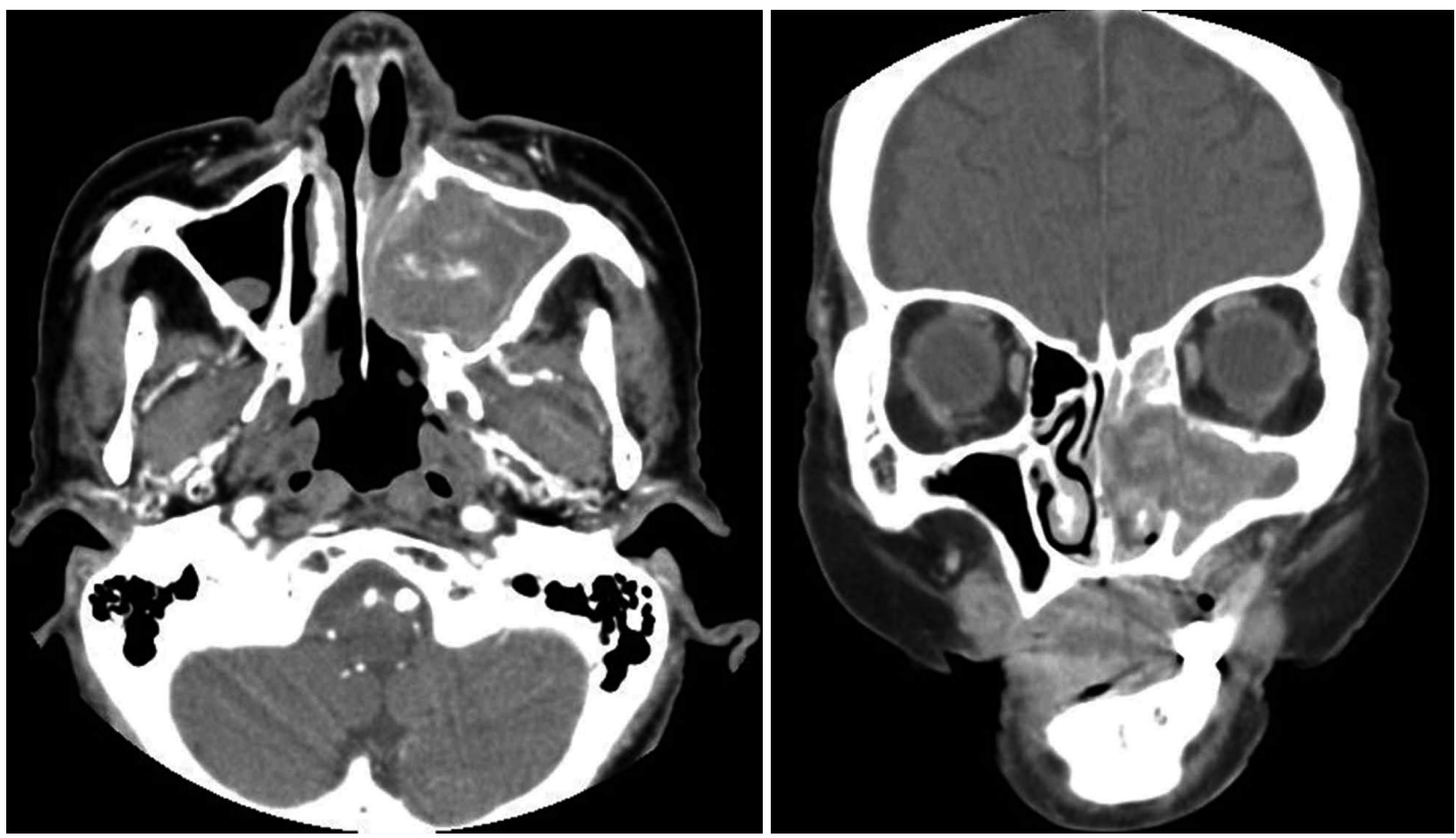

Fig. 1. Contrast-enhanced CT scan of the paranasal sinus showing a $3 \times 3.5 \mathrm{~cm}$ heterogeneous, enhancing, expansile mass associated with erosion of the medial wall, extension into the nasal cavity, and concomitant soft-tissue density within the ipsilateral ethmoid sinus.
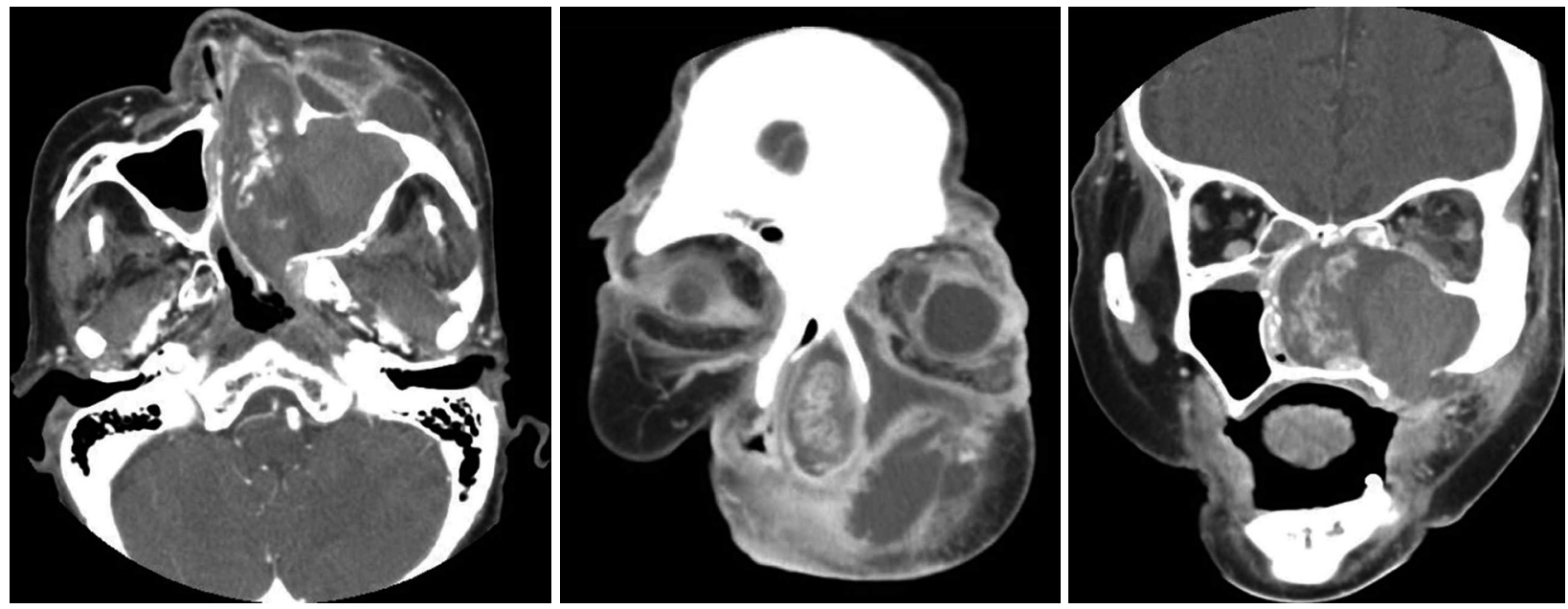

Fig. 2. Contrast-enhanced CT scan of both the orbital and paranasal sinuses shows a large, heterogeneous, enhancing mass with extensive destruction of the medial, anterior, superior, and inferior walls in the left maxillary sinus; a large multi-lobulated facial abscess, and a superomedial orbital abscess. 

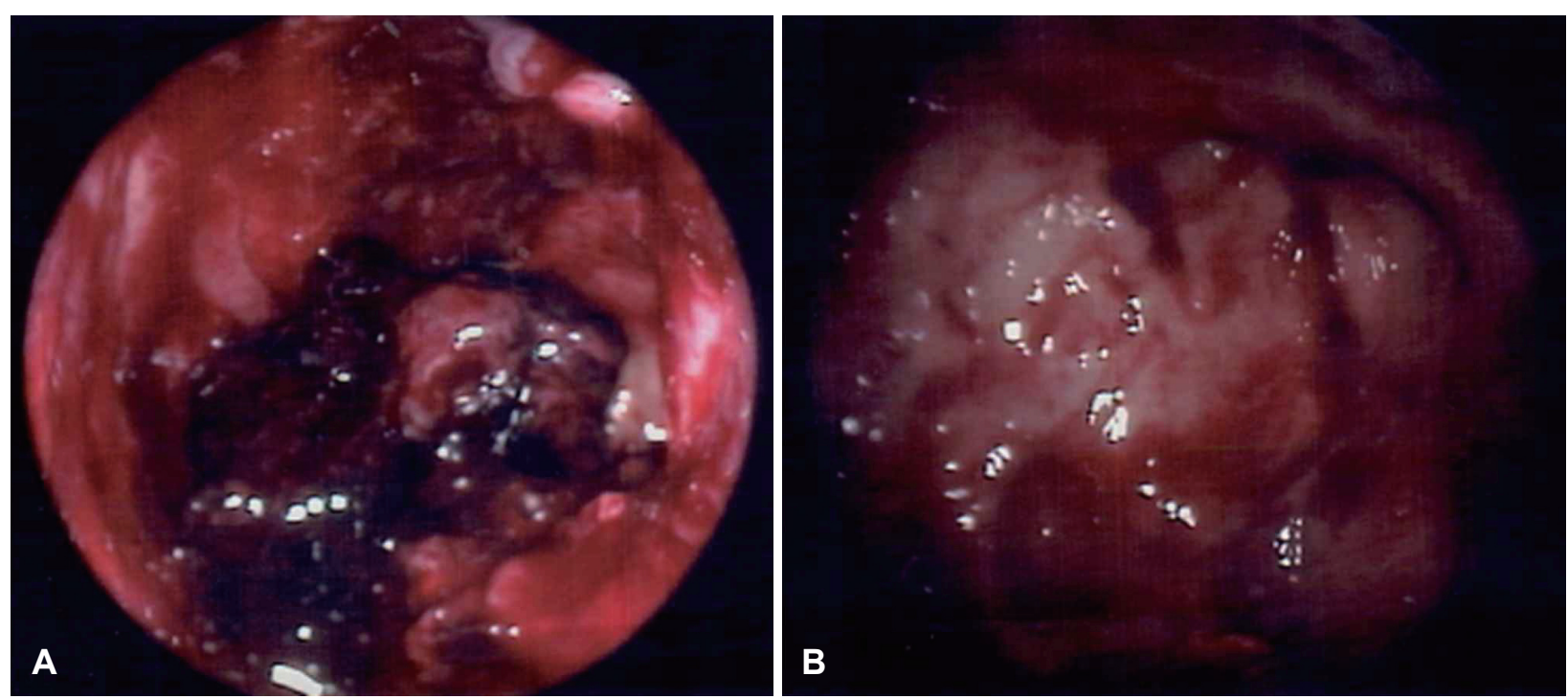

Fig. 3. Intraoperative endoscopy showing a friable, dark-reddish blood clot filling the left nasal cavity and displacing the nasal septum towards the opposite side (A). After removal of both the blood clot and the mass from the left nasal cavity, a thick fibrous granular tissue was observed within the maxillary sinus (B).

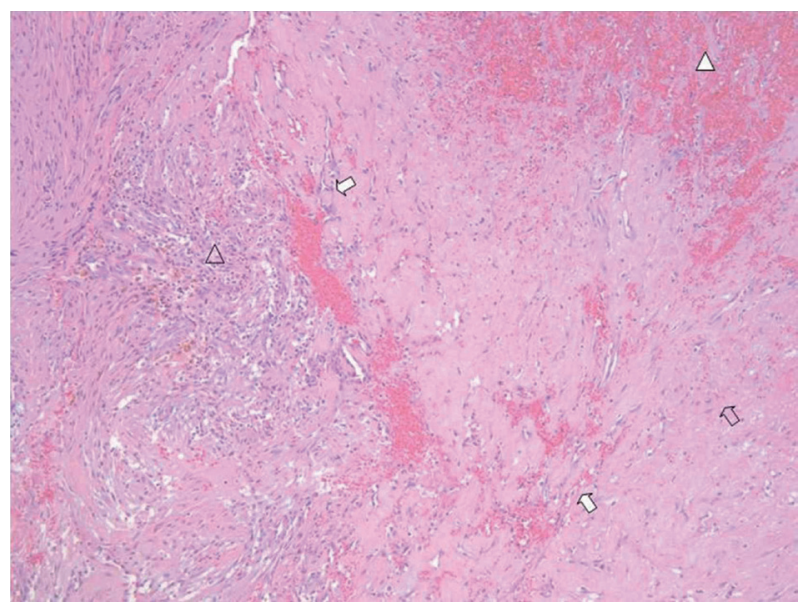

Fig. 4. Microscopic view showing an old hematoma (filled arrowhead), focal inflammation (open arrowhead), fibrosis (open arrow), and neovascularization (filled arrow) (hematoxylin \& eosin histology, $\times 100)$.

of the excised mass confirmed it to be an old hematoma with associated focal inflammation, fibrosis, and neovascularization (Fig. 4). These findings are all compatible with the diagnosis of organized hematoma. No postoperative complications occurred, and postoperative CT scans showed that the mass, which had filled left maxillary sinus, had completely resolved within 10 days of surgery. The associated abscesses had also dissipated. That said, the bone dehiscence and a mild mucosal thickening remained in the left maxillary sinus (Fig. 5). After one month, visual acuity had improved, and both gaze limitation and exophthalmos had been ameliorated.

\section{Discussion}

An OHMS is a rare clinical entity presenting as an enlarging maxillary sinus mass with locally destructive behavior. $^{4-9)}$ A typical OHMS presents with symptoms of recurrent nasal bleeding, unilateral nasal obstruction, and facial pain. ${ }^{5,9}$ Upon examination, a mass-like lesion is found in the nasal cavity, and there is often medial displacement of the lateral nasal wall toward the nasal septum. ${ }^{4-6,9)}$ In addition, CT scans reveal a large, heterogeneous, enhancing mass which causes considerable expansion of the maxillary sinus, and leads to bone erosion which varies in severity among cases. ${ }^{5,69-12)}$ In this way, the OHMS mimics a paranasal neoplasm. ${ }^{5,6,9,10)} \mathrm{Clin}-$ ical suspicion of an OHMS and preoperative biopsy both contribute to the identification of maxillary masses, and aid in determining the optimal treatment approach. ${ }^{5,6,9)}$

Neither the pathogenesis of an OHMS nor the mechanism of its rapid progression have yet been elucidated. However, it has been hypothesized that an OHMS develops in several stages as follows. Firstly, blood accumulates in the maxillary sinus. This can occur for various reasons-history of bleeding diatheses, trauma, nasal surgery, and hemorrhagic lesions such as a ruptured aneurysm and inflammatory erosions of the arterial branches supplying the maxillary sinus. Secondly, this hematoma persists in the maxillary sinus because of poor ventilation and drainage conditions. Thirdly, regardless of the initial process which led to the hematoma, the formation of a fibrous capsule around it prevents reabsorption. Neo- 

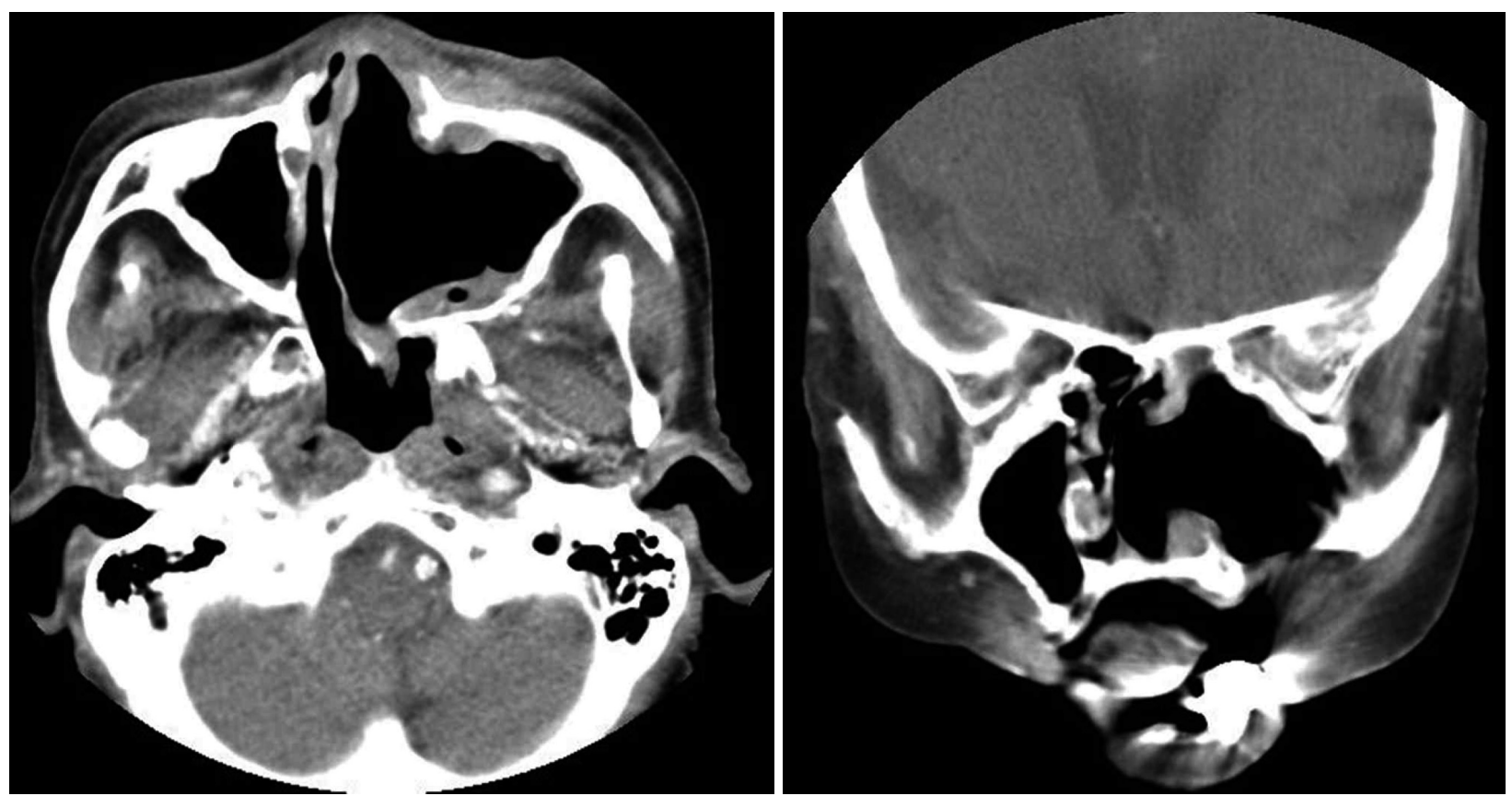

Fig. 5. A postoperative CT scan showing that the mass, which had filled the left maxillary sinus, and the abscesses had completely resolved within 10 days of surgery. The bone dehiscence and mild mucosal thickening in the left maxillary sinus remained.

vascularization ensues; with recurrent intracapsular bleeding, progressive expansion, and local bone erosion. ${ }^{2,5,6,13)}$ In our patient, the OHMS had become significantly larger in just 8 months, and there was extensive bone destruction. This rapid progression may be explicable in light of a report from Gruber, et al., ${ }^{14)}$ in which the investigators reported that platelets are activated as a consequence of vascular disruption, and secrete the contents of their granules into the developing hematoma. Platelet-released supernatants subsequently contribute to bone remodeling by stimulating formation of osteoclast-like cells through a prostaglandin/receptor activator of NF-kappaB ligand-dependent mechanism. ${ }^{14)}$

Our case also showed that OHMS has the potential to grow rapidly. For this reason, early surgical evacuation is necessary to prevent bone remodeling of the maxillary sinus and other complications. The previous studies recommended treating an OHMS using endonasal endoscopic surgery or the CaldwellLuc operation combined with endoscopic sinus surgery. ${ }^{4,69}$ ) As was seen in this case, endonasal endoscopic surgery is sufficient to completely remove even a large OHMS. Intraoperative bleeding was minimal; a finding which was in keeping with our previous case report of an OHMS. ${ }^{6}$ Regardless of the specific approach, an organized hematoma can be successfully treated by complete removal.

The predisposing factors for orbital infection are sinusitis, polyps, allergy, trauma, and dental extraction. To the best of our knowledge, this is the first report describing an intraorbital complication caused by an OHMS. Orbital complications arise from the progressive spread of inflammation along a bone dehiscence, from direct breakdown of the lamina along the vessels, and in children along open suture lines. In this case, widespread destruction of the orbital wall, caused by the expansion of the OHMS, led to an orbital abscess. We believe that the facial abscess was caused by an infection of the maxillary sinus-an extremely rare occurrence in this era of antibiotics. This infection was in turn due to the destruction of the anterior wall of the maxilla.

Orbital infection is a dangerous complication of infectious disorders of the sinuses. About $15-30 \%$ of patients who have a subperiosteal abscess will develop various visual sequelae, even with aggressive medical and surgical intervention. ${ }^{15)}$ Broad spectrum intravenous antibiotic therapy combined with sufficient surgical drainage are required to prevent vision loss. In our case, intensive treatment with surgical evacuation of the OHMS, endoscopic drainage of the orbital abscess, an additional alotomy incision and drainage of the facial abscess, and culture-directed antibiotics, all contributed to the patient's recovery.

In conclusion, early diagnosis and surgical evacuation of an OHMS are required to prevent rapid progression of the lesion, consequent destruction of the maxillary bony wall, and other suppurative complications. 


\section{REFERENCES}

1) Ozhan S, Araç M, Isik S, Oznur II, Atilla S, Kemaloglu Y. Pseudotumor of the maxillary sinus in a patient with von Willebrand's disease. AJR Am J Roentgenol 1996;166(4):950-1.

2) Tabaee A, Kacker A. Hematoma of the maxillary sinus presenting as a mass--a case report and review of literature. Int J Pediatr Otorhinolaryngol 2002;65(2):153-7.

3) Yagisawa M, Ishitoya J, Tsukuda M. Hematoma-like mass of the maxillary sinus. Acta Otolaryngol 2006;126(3):277-81.

4) Song HM, Jang YJ, Chung YS, Lee BJ. Organizing hematoma of the maxillary sinus. Otolaryngol Head Neck Surg 2007;136(4):61620.

5) Lee BJ, Lee YS, Heo SC, Kim JH, Kim YJ. Organizing hematoma of the maxillary sinus. Korean J Otolaryngol-Head Neck Surg 2002; 45(3):245-8.

6) Yoon TM, Kim JH, Cho YB. Three cases of organized hematoma of the maxillary sinus. Eur Arch Otorhinolaryngol 2006;263(9): 823-6.

7) Ohta N, Watanabe T, Ito T, Kubota T, Suzuki Y, Ishida A, et al. Clinical and pathological characteristics of organized hematoma. Int J Otolaryngol 2013;2013:539642.

8) Imayoshi S, Kanazawa T, Fukushima N, Kikuchi H, Hasegawa M, Nagatomo T, et al. Three cases of organized hematoma of the maxillary sinus: clinical features and immunohistological studies for vascular endothelial growth factor and vascular endothelial growth factor receptor 2 expressions. Case Rep Otolaryngol 2015;2015:846832.

9) Choi SJ, Seo ST, Rha KS, Kim YM. Sinonasal organized hematoma: Clinical features of seventeen cases and a systematic review. Laryngoscope 2015;125(9):2027-33.

10) Lee HK, Smoker WR, Lee BJ, Kim SJ, Cho KJ. Organized hematoma of the maxillary sinus: CT findings. AJR Am J Roentgenol 2007; 188(4):W370-3.

11) Hur J, Kim JK, Byun JS, Lee WJ. Imaging characteristics of sinonasal organized hematoma. Acta Radiol 2015;56(8):955-9.

12) Kim EY, Kim HJ, Chung SK, Dhong HJ, Kim HY, Yim YJ, et al. Sinonasal organized hematoma: CT and MR imaging findings. AJNR Am J Neuroradiol 2008;29(6):1204-8.

13) Park EH, Lee SS, Sung SH. Maxillary sinus mucocele secondary to organized hematoma. Korean J Otorhinolaryngol-Head Neck Surg 2007;50(11):1073-6.

14) Gruber R, Karreth F, Fischer MB, Watzek G. Platelet-released supernatants stimulate formation of osteoclast-like cells through a prostaglandin/RANKL-dependent mechanism. Bone 2002;30(5): 726-32.

15) Osguthorpe JD, Hochman M. Inflammatory sinus diseases affecting the orbit. Otolaryngol Clin North Am 1993;26(4):657-71. 